\title{
Structural Modifications of Residual Lignins from Sisal and Flax Pulps during Soda-AQ Pulping and TCF/ECF Bleaching
}

Jorge Rencoret, ${ }^{\dagger}$ Gisela Marques, $^{\dagger}$ Ana Gutiérrez, ${ }^{\dagger}$ Jesús Jiménez-Barbero, $^{\ddagger}$ Ángel T. Martínez, ${ }^{\ddagger}$ and José C. del Río*,†

${ }^{\dagger}$ Instituto de Recursos Naturales y Agrobiología de Sevilla, CSIC, P.O. Box 1052, E-41080-Seville, Spain

${ }^{\ddagger}$ Centro de Investigaciones Biológicas, CSIC, Ramiro de Maeztu 9, E-28040 Madrid, Spain

Supporting Information

ABSTRACT: We have studied the structural modifications of lignins from sisal and flax during their soda-anthraquinone (AQ) pulping and subsequent totally chlorine-free (TCF) and elementary chlorine-free (ECF) bleaching. For this purpose, residual lignins were isolated from pulps, analyzed by Py-GC/MS, 2D-NMR, and GPC, and their characteristics were compared to the "milled-wood" lignin of the raw materials. Soda-AQ pulping caused a preferential removal of S-lignin and cleavage of $\beta-O-4$ ' linkages, but the structure of the residual lignin remained relatively similar to native lignin. TCF bleaching barely affected the lignin structure, and noticeable amounts of $\beta-O-4^{\prime}$ linkages still occur in these pulps. In contrast, ECF bleaching caused strong modifications in the lignin structure with the complete removal of lignin markers in ECF-bleached sisal pulp. However, residual lignin was still present in ECF-bleached flax pulp, with a predominance of G- and H-lignin units and the presence of $\beta-O-4^{\prime}$ linkages.

\section{INTRODUCTION}

High-quality paper pulps are obtained by chemical pulping processes that partially depolymerize and dissolve the lignin acting as glue between wood fibers. Due to its recalcitrant nature, a certain amount of lignin remains in pulp and, because of its oxidative alteration during cooking, is responsible for the dark color of chemical pulps. The structure of residual lignin in pulps is supposed to be different from that of the lignin in raw materials and from lignin dissolved in cooking liquors. During chemical pulping, it has been reported that alkyl-aryl ethers are 'depleted', 'condensed' bonds are enriched, and new links to polysaccharides are formed. ${ }^{1-5}$

Studies on the effects of different delignification reactions on the structure of lignin in both pulp fibers and spent liquors are important in the development of new pulping and bleaching sequences. A huge amount of work has been devoted to the chemistry of alkaline pulping, particularly kraft pulping of woods. $^{3-9}$ Likewise, studies regarding the modifications of the residual lignins during bleaching have also been widely studied, again predominantly on kraft pulps. ${ }^{9-15}$ Studies regarding the chemistry of the soda-anthraquinone (AQ) pulping, often applied to nonwoody lignocellulosic materials, have been comparatively scarce. ${ }^{1,2,16,17}$

In this work, we studied the chemical modifications of the lignin during soda-AQ pulping of two nonwoody materials, sisal and flax fibers, and their subsequent TCF and ECF bleaching. Sisal and flax fibers were selected because of their very different lignin content and composition. Sisal presents a higher lignin content (12\% Klason lignin) and is enriched in syringyl (S) lignin $(S / G$ ratio of 4$),{ }^{18-20}$ while flax presents lower lignin content (4\% Klason lignin) and is extremely enriched in guaiacyl $(G)$ units $(S / G$ ratio of 0.1$) \cdot{ }^{18,21}$ In this work, the residual lignins from bleached and unbleached pulps were isolated by acidolysis, which is a widely used and efficient method for obtaining lignin in high yield and purity from pulp, ${ }^{6}$ and compared to the structure of the "milled-wood lignin" (MWL) isolated from the same raw materials, a lignin preparation that is considered to be the most representative of the native lignin in the plant.

The structural characteristics of the residual lignins and their corresponding MWLs were analyzed by pyrolysis-gas chromatography-mass spectrometry (Py-GC/MS) and two-dimensional nuclear magnetic resonance (2D-NMR). Py-GC/MS is a rapid and highly sensitive technique for characterizing the chemical composition of lignin ${ }^{18,22-24}$ and has previously been applied to the characterization of residual lignins "in situ" in pulps. ${ }^{11}$ Additional information regarding the different interunit linkages present in the lignin polymer was provided by $2 \mathrm{D}$ NMR spectroscopy, a powerful tool for lignin structural characterization. ${ }^{9,20,21,25-34}$ Finally, the molecular weights of the isolated residual lignins were estimated by Gel Permeation Chromatography (GPC) and compared with those of their respective MWLs, to obtain further information about depolymerization/condensation reactions during pulping and bleaching.

The detailed knowledge of the structure of the residual lignins in pulp will provide useful information of the structural changes produced during soda-AQ pulping as well as during TCF and ECF bleaching. Increasing the knowledge of the chemistry of delignification and bleaching will facilitate the search for technical solutions aiming at increasing pulping and bleaching efficiency.

Received: October 15, 2012

Revised: $\quad$ March 4, 2013

Accepted: March 9, 2013

Published: March 9, 2013 


\section{MATERIAL AND METHODS}

2.1. Raw Material and Pulp Samples. Sisal and flax fibers and their unbleached (after soda-AQ pulping) and fully bleached (TCF and ECF) pulps were supplied by CELESA pulp mill (Tortosa, Spain). General conditions of soda-AQ pulping included the use of sodium hydroxide and anthraquinone (up to $0.05 \%$ ) as cooking chemicals and 2-4 $\mathrm{h}$ of cooking time at a temperature of about $160-170{ }^{\circ} \mathrm{C}$. The TCF bleaching sequence used (Q-Po) included a quelating stage $(\mathrm{Q})$ and a hydrogen peroxide stage under pressurized oxygen (Po). The ECF bleaching sequence used (D-Po) included a chlorine dioxide stage (D) followed by a hydrogen peroxide stage under pressurized oxygen (Po). The kappa index of the unbleached pulps were 10 and 12; for TCF pulps were 2 and 3; and for ECF pulps were 0.5 and 1, for sisal and flax pulps, respectively.

2.2. MWL Isolation. Sisal and flax fibers were air-dried and milled using a knife mill and successively extracted with acetone in a Soxhlet apparatus for $8 \mathrm{~h}$ and with hot water $(3 \mathrm{~h}$ at 100 $\left.{ }^{\circ} \mathrm{C}\right)$. The MWLs were obtained according to the classical procedure. ${ }^{35}$ Extractive free samples (prepared as above) were finely ball-milled in a Retsch PM100 planetary mill ( $40 \mathrm{~h}$ at 400 rpm for $25 \mathrm{~g}$ of material) using a $500 \mathrm{~mL}$ agate jar and agate ball bearings $(20 \times 20 \mathrm{~mm})$ and toluene as coolant. The milled samples were submitted to an extraction $(3 \times 12 \mathrm{~h})$ with dioxane:water $(9: 1, \mathrm{v} / \mathrm{v})(20 \mathrm{~mL}$ solvent/g milled sample). The suspension was centrifuged, and the supernatant was evaporated at $40{ }^{\circ} \mathrm{C}$ under reduced pressure. The residue obtained (raw MWL) was redissolved in acetic acid/water 9:1 (v/v) $(25 \mathrm{~mL}$ solvent/g raw MWL). The solution was then precipitated into stirred cold water, and the residue was separated by centrifugation, milled in an agate mortar, and dissolved in 1,2-dichloroethane:ethanol $(2: 1, \mathrm{v} / \mathrm{v})$. The mixture was then centrifuged to eliminate the insoluble material. The resulting supernatant was precipitated into cold diethyl ether, centrifuged, and subsequently resuspended in $30 \mathrm{~mL}$ of petroleum ether and centrifuged again to obtain the purified MWL, which was dried under a current of $\mathrm{N}_{2}$. The final yields ranged from 15 to $20 \%$ based on the Klason lignin content.

2.3. Isolation of the Residual Lignins. The isolation of the residual lignins was performed by acid hydrolysis according to the procedure already described. ${ }^{6}$ The extractives-free pulp sample (100 g dry weight) was refluxed for $2 \mathrm{~h}$ with $150 \mathrm{~mL}$ of $0.1 \mathrm{M} \mathrm{HCl}$ in dioxane-water 82:18 (v/v) under nitrogen. The pulp was then filtered and washed with dioxane-water 82:18. The filtrate was evaporated at $40{ }^{\circ} \mathrm{C}$, and then the lignin was precipitated in water. The precipitated lignin was then centrifuged and subsequently freeze-dried. After freeze-drying, the lignins were Soxhlet extracted with pentane during $8 \mathrm{~h}$ to remove lipid extractives. The lignins were then finally washed with chloroform in order to remove fatty acid salts. The yields of the residual lignins were around $40 \%$ for the sisal pulps and around $15 \%$ for the flax pulps (based on the lignin content obtained according their kappa numbers). The isolated residual lignins presented a dark brown color, except for the material isolated from sisal ECF pulp, which presented a whitish color, indicating the presence of salts in this isolated material.

2.4. Py-GC/MS. Pyrolysis of the isolated residual lignins (approximately $100 \mu \mathrm{g}$ ) was performed with a 2020 microfurnace pyrolyzer (Frontier Laboratories Ltd.) connected to an Agilent $6890 \mathrm{GC} / \mathrm{MS}$ system equipped with a DB-1701 (Agilent J\&W) fused-silica capillary column $(30 \mathrm{~m} \times 0.25$ mm i.d., $0.25 \mu \mathrm{m}$ film thickness) and an Agilent 5973 mass selective detector $(\mathrm{EI}$ at $70 \mathrm{eV})$. The pyrolysis was performed at $500{ }^{\circ} \mathrm{C}$. The oven temperature was programmed from $40{ }^{\circ} \mathrm{C}(1$ min) to $300{ }^{\circ} \mathrm{C}$ at $6{ }^{\circ} \mathrm{C} \mathrm{min}^{-1}(10 \mathrm{~min})$. Helium was the carrier gas $\left(1 \mathrm{~mL} \mathrm{~min}^{-1}\right)$. The compounds were identified by comparing their mass spectra with those of the Wiley and NIST libraries and reported in the literature. ${ }^{23,24}$ Peak molar areas (obtained by dividing the peak area by the molecular weight) were calculated for the lignin-derived products, the summed molar areas were normalized to 100 , and the data for two repetitive analyses were averaged and expressed as percentages. The relative standard deviation for the pyrolysis data was $<5 \%$. No attempt was made to calculate the response factor for every single compound released. However, for most of the lignin derived phenols, the response factors were nearly identical, ${ }^{36}$ with the exception of vanillin, but this was a minor peak here.

2.5. NMR Spectroscopy. NMR spectra of isolated lignins were recorded at $25{ }^{\circ} \mathrm{C}$ on a Bruker AVANCE $500 \mathrm{MHz}$ equipped with a z-gradient triple resonance probe. Around 40 $\mathrm{mg}$ of lignin was dissolved in $0.75 \mathrm{~mL}$ of deuterated dimethylsulfoxide (DMSO- $d_{6}$ ), and 2D-NMR spectra were recorded in HSQC (heteronuclear single quantum coherence) experiments using Bruker's 'hsqcetgp' pulse program with spectral widths of 5000 and $13200 \mathrm{~Hz}$ for the ${ }^{1} \mathrm{H}-$ and ${ }^{13} \mathrm{C}$ dimensions, respectively. The number of collected complex points was 2048 for ${ }^{1} \mathrm{H}$-dimension with a recycle delay of $1 \mathrm{~s}$. The number of transients was 64, and 256 time increments were always recorded in ${ }^{13} \mathrm{C}$-dimension. The ${ }^{1} J_{\mathrm{CH}}$ used was 140 $\mathrm{Hz}$. Processing used typical matched Gaussian apodization in the ${ }^{1} \mathrm{H}$ dimension and squared cosine-bell apodization in the ${ }^{13} \mathrm{C}$ dimension. Prior to Fourier transformation, the data matrixes were zero filled up to 1024 points in the ${ }^{13} \mathrm{C}$ dimension. The central solvent peak was used as an internal reference $\left(\delta_{\mathrm{C}} 39.5 ; \delta_{\mathrm{H}} 2.49\right)$. HSQC cross-signals were assigned by comparing with the literature. ${ }^{9,20,21,25-34} \mathrm{~A}$ semiquantitative analysis of the intensities of the HSQC cross-signal intensities was performed. First, cross-signals integration was performed separately for the different regions of the spectra, which contain chemically-analogous carbon-proton pairs. In the aliphatic oxygenated region, the relative abundance of the different interunit linkages was estimated from $\mathrm{C}_{\alpha}-\mathrm{H}_{\alpha}$ correlations, and the relative abundance of side-chains involved in the different interunit linkages was calculated. In the aromatic region, $\mathrm{C}_{2,6^{-}}$ $\mathrm{H}_{2,6}$ correlations from $\mathrm{S}$ units, $\mathrm{C}_{2}-\mathrm{H}_{2}$ correlations from $\mathrm{G}$ units, and $\mathrm{C}_{2,6}-\mathrm{H}_{2,6}$ correlations from $p$-hydroxycinnamyl $(\mathrm{H})$ units were used to estimate the H:G:S lignin ratios. The abundances of the different interunit linkages were referred to the number of aromatic units (as per 100 aromatic units), to obtain a comparative estimation of their removal during pulping and bleaching. Finally, an estimation of the percentage of $\gamma$-acylation of the lignin side-chain was performed by integration of the signals corresponding to the hydroxylated vs acylated $\mathrm{C}_{\gamma}-\mathrm{H}_{\gamma}$ correlations in the $\mathrm{HSQC}$ spectra of the isolated lignins.

2.6. Gel Permeation Chromatography (GPC). GPC analysis was performed using a Waters size exclusion chromatographic system with a Waters 2487 UV detector at $280 \mathrm{~nm}$. The analyses were carried out at room temperature using THF as the eluent, at a flow rate of $1 \mathrm{~mL} \mathrm{~min}$. The samples were dissolved in THF and injected into three Ultrastyragel columns (HR 2.5, HR2, and HR 4) coupled in series. The GPC system was calibrated with polystyrene 
Table 1. Structural Characteristics (Percentage of the H-, G-, and S-Lignin units, H/G and S/G Ratios, Percentage of Lignin Markers Bearing Side-Chains of 0-1 Carbon Atoms, and Percentage of Lignin Markers Bearing a Carboxyl/Carbonyl Group at the $\alpha$-Carbon) from the Py-GC/MS of the Residual Lignins Isolated from Sisal and Flax Pulps and Their Respective MWL

\begin{tabular}{|c|c|c|c|c|c|c|c|c|}
\hline & \multirow[b]{2}{*}{ sisal MWL } & \multicolumn{3}{|c|}{ sisal pulps } & \multirow[b]{2}{*}{ flax MWL } & \multicolumn{3}{|c|}{ flax pulps } \\
\hline & & unbleached & TCF & ECF & & unbleached & TCF & ECF \\
\hline$\% \mathrm{H}$ & 1.0 & 3.7 & 2.4 & - & 10.8 & 11.0 & 10.5 & 38.0 \\
\hline$\% \mathrm{G}$ & 22.1 & 32.0 & 27.8 & - & 74.0 & 79.3 & 81.5 & 62.0 \\
\hline$\%$ S & 76.9 & 64.3 & 69.8 & - & 15.2 & 9.7 & 8.0 & 0.0 \\
\hline $\mathrm{H} / \mathrm{G}$ & $<0.1$ & 0.1 & 0.1 & - & 0.1 & 0.1 & 0.1 & 0.6 \\
\hline$S / G$ & 3.5 & 2.1 & 2.4 & - & 0.2 & 0.1 & 0.1 & 0.0 \\
\hline$\% \mathrm{Ph}-\mathrm{C}_{0-1}{ }^{a}$ & 45.4 & 52.2 & 50.9 & - & 54.0 & 55.4 & 53.2 & 70.0 \\
\hline$\% \mathrm{Ph}-\mathrm{C}=\mathrm{O}^{b}$ & 10.3 & 9.7 & 9.9 & - & 7.5 & 8.6 & 9.4 & 20.5 \\
\hline
\end{tabular}

${ }^{a}$ Percentage of lignin phenolic markers bearing side-chains of $0-1$ carbon atoms. ${ }^{b}$ Percentage of lignin phenolic markers bearing a carboxyl/carbonyl group at the $\alpha$-carbon.

standards in the molecular weight range of from 1890 to 17900 $\mathrm{g} \mathrm{mol}^{-1}$. The weight-average molecular weights $\left(M_{\mathrm{w}}\right)$, number average molecular weights $\left(M_{\mathrm{n}}\right)$, and the polydisperisities (ratios $M_{\mathrm{w}} / M_{\mathrm{n}}$ ) were calculated.

\section{RESULTS AND DISCUSSION}

The effect of soda-AQ pulping and TCF/ECF bleaching on the lignins of sisal and flax fibers was investigated. For this purpose, the residual lignins were isolated from unbleached, TCF- and ECF-bleached soda-AQ pulps from sisal and flax fibers, and their structural characteristics were thoroughly analyzed by PyGC/MS and 2D-NMR and compared to that of the MWLs isolated from the respective raw material. In addition, the molecular weights of the residual lignins and their respective MWLs were estimated by GPC to obtain further information about the degradation/condensation reactions that eventually may have taken place. This study will give a better understanding of the chemical composition and behavior of residual lignin in alkaline pulps and the effect of the different bleaching stages on its structure.

The pyrograms of the residual lignins isolated from unbleached and from TCF- and ECF-bleached sisal and flax pulps are shown in Figures $\mathrm{S} 1$ and S2, respectively. The pyrograms of their corresponding MWLs are also shown for comparison. The identities and relative molar abundances of the released lignin-derived compounds are listed in Table S1. The relative abundance of the $\mathrm{H}$-, G-, and S-lignin units and $\mathrm{H}$ / $\mathrm{G}$ and $\mathrm{S} / \mathrm{G}$ ratios as well as the percentage of lignin markers bearing shorter (0-1 carbon atoms) side-chains or a carboxyl/ carbonyl group at $\mathrm{C} \alpha$ are shown in Table 1. The HSQC spectra of the residual lignins isolated from the different sisal and flax pulps as well as their corresponding MWLs are shown in Figures 1 and 2, respectively. The main lignin cross-signals assigned in the HSQC spectra are listed in Table S2, and the main lignin substructures found are depicted in Figure 3. The structural characteristics (abundance of the main interunit linkages, percentage of $\gamma$-acylation, relative abundance of main units, and $H / G$ and $S / G$ ratios) obtained from the HSQC spectra of the residual lignins from the different pulps and their respective MWLs are reflected in Table 2. Finally, the weightaverage molecular weights $\left(M_{\mathrm{w}}\right)$, the number average molecular weights $\left(M_{\mathrm{n}}\right)$, and the polydisperisities (ratio $M_{\mathrm{w}} / M_{\mathrm{n}}$ ) of the residual lignins were calculated from the GPC curves and compared to those of the respective MWLs (Table 3).

3.1. Effect of the Soda-AQ Pulping on the Lignin Structure. The pyrogram of the sisal MWL (Figure S1) indicated that this lignin was enriched in S-lignin units, as already reported in previous papers. ${ }^{18-20}$ The main ligninderived compounds released were guaiacol (5), 4-methylguaiacol (9), 4-ethylguaiacol (10), 4-vinylguaiacol (12), syringol (13), 4-methylsyringol (19), trans-isoeugenol (20), 4-ethylsyringol (23), 4-vinylsyringol (25), 4-allylsyringol (26), cis-4propenylsyringol (29), syringaldehyde (30), trans-4-propenylsyringol (31), and trans-sinapaldehyde (35). The Py-GC/MS data (Table 1) indicate a 1:22:77 (H:G:S) relative composition and a high $\mathrm{S} / \mathrm{G}$ ratio of 3.5 for sisal MWL. Interestingly, the residual lignin isolated from the unbleached sisal soda-AQ pulp presented a pyrogram similar to that of the MWL (Figure S1), with a high predominance of S-lignin compounds (H:G:S composition being 4:32:64; Table 1), although their relative abundances clearly decreased with respect to the G-lignin units, resulting in a reduction of the $S / G$ ratio to 2.1. This fact indicates a preferential removal of the $S$-lignin moieties in sisal during soda-AQ pulping, as also occurred during kraft pulping, although the unbleached pulp still retains a residual lignin with a high S/G ratio. Compounds with intact C3-side-chain (i.e., peaks 26: 4-allylsyringol, 29: cis-4-propenylsyringol, and 31: trans-4-propenylsyringol) were also preferentially removed, indicating cleavage of the lignin side-chain. However, no major structural oxidation was observed in this residual lignin, as shown by the relatively low presence of $\mathrm{C} \alpha$-oxidized lignin compounds (i.e., peaks 30: syringaldehyde, 32: acetosyringone, and 34: propiosyringone) in the pyrogram of the residual lignin (Table S1).

In the case of flax, the pyrogram of its MWL was completely different from that of sisal, releasing predominantly compounds derived from G-lignin units, with minor amounts of compounds derived from S- and H-lignin (Figure S2). The major lignin compounds released from this lignin were 4-methylphenol (4), guaiacol (5), 4-methylguaiacol (9), 4-ethylguaiacol (10), 4vinylguaiacol (12), syringol (13), 4-methylsyringol (19), transisoeugenol (20), guaiacylacetone (24), 4-vinylsyringol (25), and trans-4-propenylsyringol (31). The Py-GC/MS data (Table 1) indicate a $11: 74: 15$ (H:G:S) relative composition and a low S/G ratio of 0.2 for flax MWL. The pyrogram of the residual lignin from unbleached flax pulp was similar to that of the MWL and also released predominantly compounds derived from G-lignin units, the major lignin compounds being similar to those released from the MWL (Figure S2). A slight decrease in the relative abundances of S-units, together with a concomitant increase of the relative abundances of G-units (H:G:S composition being 11:79:10; Table 1), was observed in the unbleached soda-AQ pulp, thus resulting in a decrease of the $S / G$ ratio to 0.1 . This fact indicates that S-lignin units, 

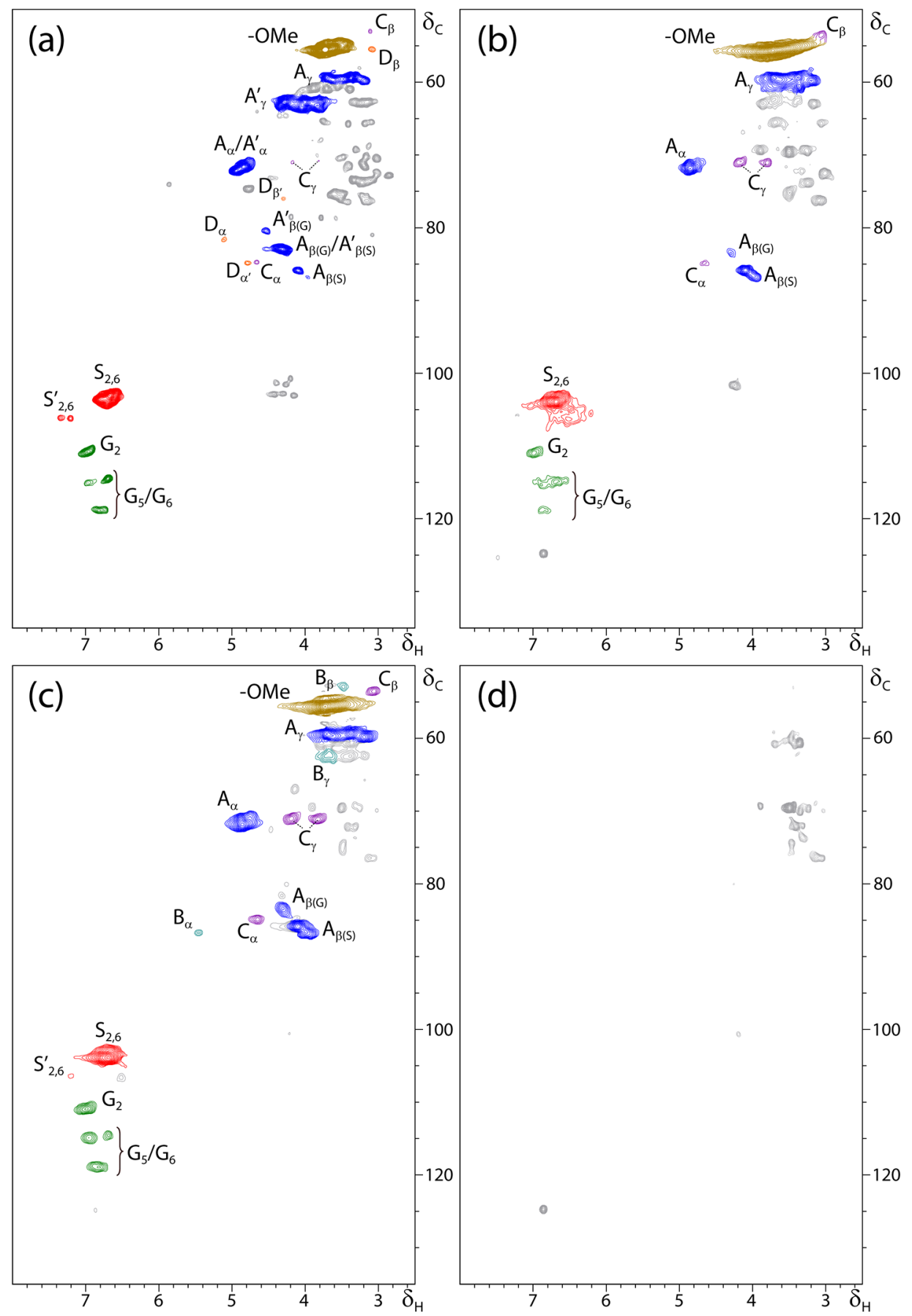

Figure 1. HSQC NMR spectra $\left(\delta_{\mathrm{C}} / \delta_{\mathrm{H}} 50-135 / 2.5-8.0 \mathrm{ppm}\right)$ of the MWL from sisal fibers $(\mathbf{a})$ and the residual lignins from unbleached soda-AQ sisal pulp (b), TCF-bleached sisal pulp (c), and ECF-bleached sisal pulp (d). See Table S2 for signal assignment and Figure 3 for the main lignin structures identified.

which are present in low amounts in flax fibers, are preferentially removed during soda-AQ pulping, as also observed in sisal. Thus, soda-AQ pulping produced an unbleached flax pulp with a residual lignin being extremely enriched in G-units. We should discharge the increase in the relative abundance of $\mathrm{G}$ units as being due to demethoxylation reactions occurring during pulping. In fact, demethoxylation reactions reported during alkaline cooking is actually exclusively demethylation reactions, producing catechol moieties, which, certainly, are not G-lignin units. In any case, catechol moieties did not show up in our analyses (Py-GC/MS or 2D-NMR). Finally, no major structural oxidation was observed in the pyrogram of the residual lignin from unbleached flax pulp compared to the MWL, as shown by the relatively low amounts of $\mathrm{C} \alpha$-oxidized lignin compounds (i.e., peaks 18: vanillin, 21: acetoguaiacone, and 27: propiovanillone) in the pyrogram of the residual lignin (Figure S2, Table S1), as also observed in sisal.

The HSQC spectra of the residual lignins and their respective MWLs gave additional information about the different interunit linkages present in their structures. In the side-chain region of the spectra, cross-signals from methoxyls and side-chains in $\beta-O-4^{\prime}$-substructures (A) were the most prominent. In addition to these, cross-signals from other 

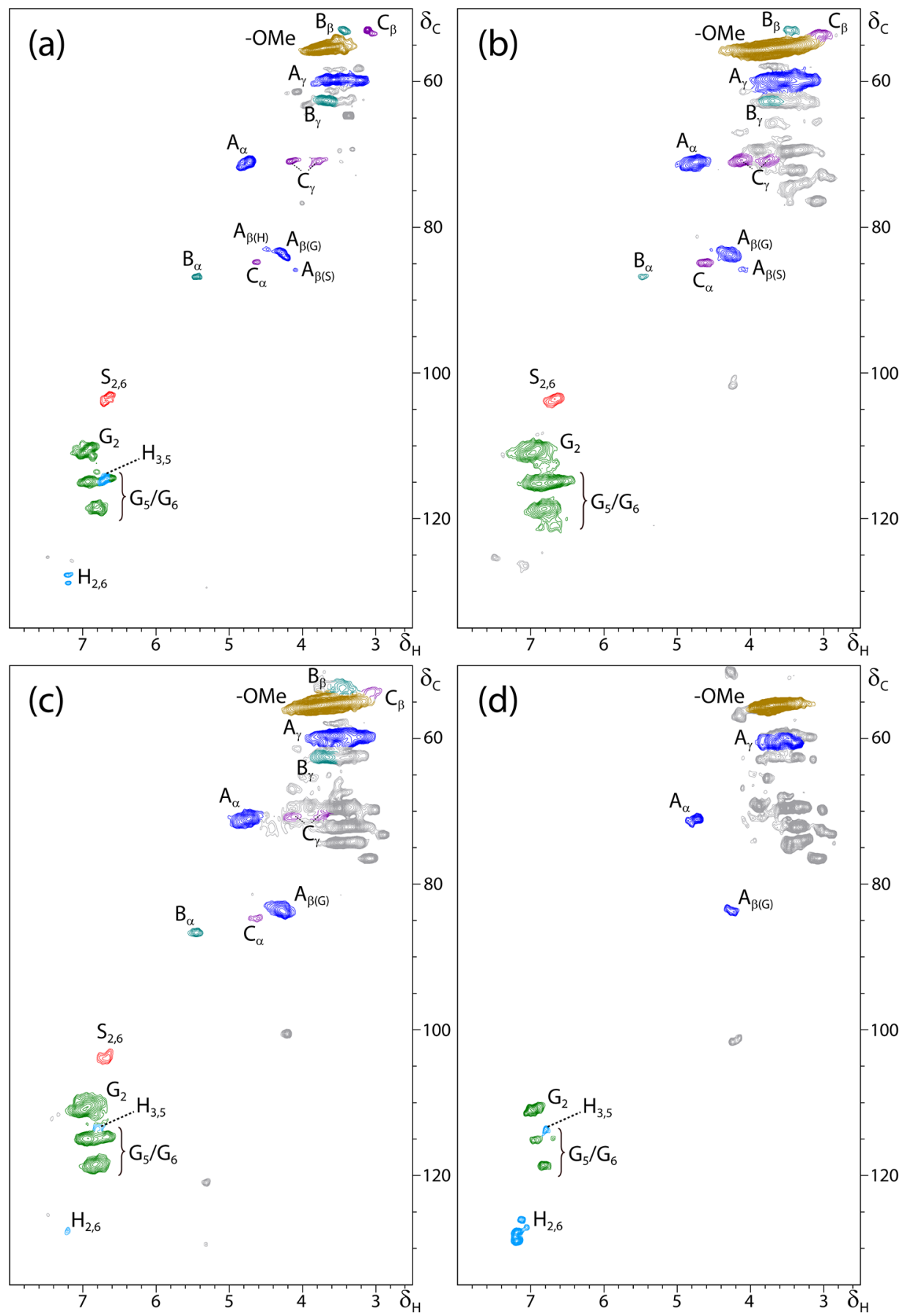

Figure 2. HSQC NMR spectra $\left(\delta_{\mathrm{C}} / \delta_{\mathrm{H}} 50-135 / 2.5-8.0 \mathrm{ppm}\right)$ of the flax MWL $(\mathbf{a})$ and the residual lignins from unbleached soda-AQ flax pulp $(\mathbf{b})$, TCF-bleached flax pulp (c), and ECF-bleached flax pulp (d). See Table S2 for signal assignment and Figure 3 for the main lignin structures identified.

substructures, including phenylcoumarans (B), and resinols (C), were observed in all the lignins. Moreover, spirodienones (D) were also observed, although in low amounts, in the HSQC spectra of the MWL of sisal and flax fibers but could not be detected in the spectra of the residual lignins. Interestingly, a strong signal was observed in the HSQC spectrum of sisal MWL in the range $\delta_{\mathrm{C}} / \delta_{\mathrm{H}} 62.7 / 3.83-4.19$, corresponding to the $\mathrm{C}_{\gamma}-\mathrm{H}_{\gamma}$ correlations in $\gamma$-acylated lignin units $\left(\mathrm{A}^{\prime}\right)$. This agrees with previous studies ${ }^{18-20}$ indicating that the lignin from sisal is highly acetylated at the $\gamma$-carbon of the side chain and exclusively with acetate groups. On the other hand, the main cross-signals in the aromatic region of the HSQC spectra corresponded mainly to the substituted benzenic rings of the different $S, G$, and $H$ lignin units. Signals of $H$ lignin units were only detected in the HSQC spectra of flax lignins, being especially abundant in the residual lignin from ECF flax pulp, as already observed by Py-GC/MS. The abundances of the main interunit linkages (referred to as per 100 aromatic units) present in the residual lignins (and their corresponding MWL) samples as well as the percentage of $\gamma$-acetylation of the lignin side-chain, the relative abundance of the $H, G$, and $S$ units, and the $\mathrm{H} / \mathrm{G}$ and $\mathrm{S} / \mathrm{G}$ ratios, calculated from the HSQC spectra of the isolated residual lignins, are shown in Table 2. 
<smiles>CCOc1c(C)cc(C(Oc2c(C)cc(C)cc2C)C([CH]O)C(O)c2cc(C)cc(OC)c2)cc1OC</smiles>

A

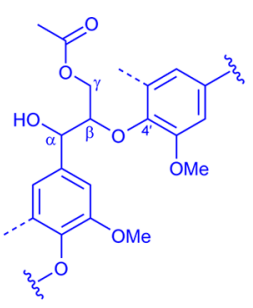

$A^{\prime}$

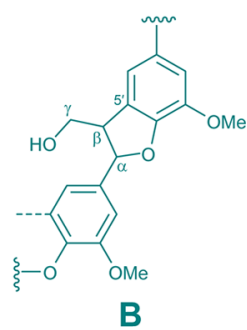

B<smiles>CCOc1c(C)cc(C2OCC3C2OC[C@H]3c2cc(OC)c(OCC)c(OC)c2)cc1OC</smiles>

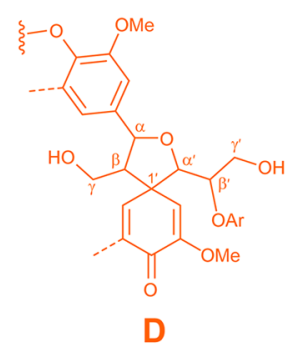

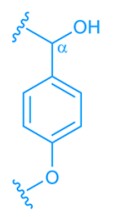

$\mathrm{H}$

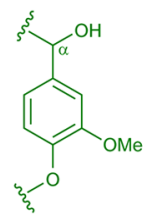

G

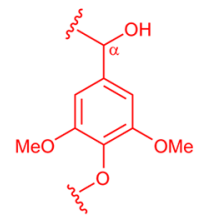

$\mathrm{S}$

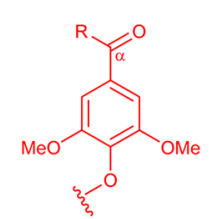

$S^{\prime}$
Figure 3. Main structures present in the residual lignins isolated from the different pulps. (A) $\beta-O-4^{\prime}$ alkyl-aryl ethers; $\left(\mathbf{A}^{\prime}\right) \gamma$-acetylated $\beta-$ $O-4^{\prime}$ alkyl-aryl ethers; (B) $\beta-5^{\prime}$ phenylcoumarane substructures; (C) $\beta-\beta^{\prime}$ resinol substructures; (D) $\beta-1^{\prime}$ spirodienone substructures; (H) $p$-hydroxyphenyl units; (G) guaiacyl units; (S) syringyl units; $\left(\mathbf{S}^{\prime}\right) \mathrm{C} \alpha$ oxidized syringyl units.

The HSQC spectrum of sisal MWL (Figure 1a) confirmed, in agreement with the Py-GC/MS data shown above, that this lignin is extremely enriched in S-lignin units (S/G 4.0). In addition, the NMR indicated the presence of high amounts of $\beta-O-4^{\prime}$ alkyl-aryl ether linkages (80 substructures per 100 aromatic units) and only low amounts of condensed substructures such as phenylcoumarans (3 substructures per 100 aromatic units), resinols (2 substructures per 100 aromatic
Table 3. Weight-Average $\left(M_{\mathrm{w}}\right)$ and Number-Average $\left(M_{\mathrm{n}}\right)$ Molecular Weights and Polydispersity $\left(M_{w} / M_{n}\right)$ of the Residual Lignins Isolated from Sisal and Flax Pulps and Their Respective MWLs

\begin{tabular}{llcc}
\multicolumn{1}{c}{ sample } & $M_{\mathrm{w}}\left(\mathrm{g} \mathrm{mol}^{-1}\right)$ & $\mathrm{Mn}\left(\mathrm{g} \mathrm{mol}^{-1}\right)$ & $M_{\mathrm{w}} / M_{\mathrm{n}}$ \\
sisal MWL & 4700 & 3050 & 1.54 \\
sisal unbleached pulp (peak 1) & 1350 & 1160 & 1.16 \\
sisal unbleached pulp (peak 2) & 4050 & 3280 & 1.23 \\
sisal TCF pulp (peak 1) & 1030 & 640 & 1.61 \\
sisal TCF pulp (peak 2) & 3500 & 3150 & 1.11 \\
sisal ECF pulp & - & - & - \\
flax MWL & 7620 & 2120 & 3.59 \\
flax unbleached pulp (peak 1) & 1390 & 1200 & 1.16 \\
flax unbleached pulp (peak 2) & 3890 & 3300 & 1.18 \\
flax TCF pulp (peak 1) & 1390 & 1140 & 1.22 \\
flax TCF pulp (peak 2) & 3890 & 3440 & 1.13 \\
flax ECF pulp (peak 1) & 1650 & 1410 & 1.17 \\
flax ECF pulp (peak 2) & 5300 & 4420 & 1.20 \\
\hline
\end{tabular}

units), and spirodienones (4 substructures per 100 aromatic units). In addition, the HSQC spectrum indicated that this lignin is highly acetylated at the $\gamma$-carbon of the lignin sidechain, as already reported in previous papers. ${ }^{18-20}$ The percentage of acetylation of the lignin side chain was estimated from the $\mathrm{C}_{\gamma}-\mathrm{H}_{\gamma}$ correlations and accounted for about $68 \%$ of all side-chains. Comparison with the HSQC spectrum of the residual lignin from unbleached sisal soda-AQ pulp (Figure 1b) provided important information of the structural changes produced during soda-AQ pulping. Thus, the HSQC spectrum of the residual lignin revealed the complete absence of acetylation of the $\gamma$-carbon of the lignin side-chain, indicating that acetates have been completely hydrolyzed and removed during soda-AQ pulping. Additionally, a large removal of the $\beta-O-4^{\prime}$ alkyl-aryl ether linkages occurred during pulping, although important amounts of these linkages still remained in the residual lignin. However, perhaps due to their low amounts, the abundances of the condensed lignin substructures resinols and phenylcoumarans were barely affected by soda- $\mathrm{AQ}$ pulping. In agreement with the Py-GC/MS data, no oxidized lignin moieties were observed in the HSQC spectrum of the residual lignin from unbleached sisal pulp, as reflected by the absence of the corresponding signal at $\delta_{\mathrm{C}} / \delta_{\mathrm{H}} 82.8 / 5.23$ for the $\mathrm{C}_{\beta}-\mathrm{H}_{\beta}$

Table 2. Structural Characteristics (Abundance of the Main Interunit Linkages, Percentage of $\gamma$-Acylation, Relative Abundance of Main Lignin Units and H/G and S/G Ratios) Observed from the HSQC Spectra of the Residual Lignins Isolated from Sisal and Flax Pulps and Their Respective MWLs

\begin{tabular}{|c|c|c|c|c|c|c|c|c|}
\hline & \multirow[b]{2}{*}{ sisal MWL } & \multicolumn{3}{|c|}{ sisal pulps } & \multirow[b]{2}{*}{ flax MWL } & \multicolumn{3}{|c|}{ flax pulps } \\
\hline & & unbleached & TCF & ECF & & unbleached & TCF & ECF \\
\hline \multicolumn{9}{|c|}{ linkage abundance (per 100 aromatic units) } \\
\hline$\beta-O-4$ alkyl-aryl ethers & 80 & 60 & 71 & - & 52 & 45 & 47 & 35 \\
\hline phenylcoumarans & 3 & 2 & 2 & - & 12 & 10 & 8 & 0 \\
\hline resinols & 2 & 2 & 2 & - & 5 & 5 & 4 & 0 \\
\hline spirodienones & 4 & 0 & 0 & - & 1 & 0 & 0 & 0 \\
\hline percentage of $\gamma$-acylation & 68 & 0 & 0 & - & 0 & 0 & 0 & 0 \\
\hline \multicolumn{9}{|l|}{ composition of lignin units } \\
\hline$\overline{\mathrm{H}}$ & 0 & 0 & 0 & - & 3 & 6 & 6 & 32 \\
\hline G & 20 & 25 & 23 & - & 88 & 85 & 85 & 68 \\
\hline S & 80 & 75 & 77 & - & 9 & 9 & 9 & 0 \\
\hline $\mathrm{H} / \mathrm{G}$ & 0.0 & 0.0 & 0.0 & - & 0.0 & 0.1 & 0.1 & 0.5 \\
\hline$S / G$ & 4.0 & 3.0 & 3.3 & - & 0.1 & 0.1 & 0.1 & 0.0 \\
\hline
\end{tabular}


correlation in $\alpha$-oxidized $\beta-O-4^{\prime}$ substructures and the lack of the corresponding $\alpha$-oxidized S-lignin units $\left(\mathrm{S}^{\prime}\right)$ in the HSQC spectrum of the residual lignin. Stilbenes, found in kraft lignins, could not be detected in the unbleached pulp lignin. Similar results have been reported in other pulp residual lignins, ${ }^{9}$ suggesting that these compounds are formed during cooking and released to the soluble lignin fraction. The HSQC spectrum also confirmed the decrease of the $S / G$ ratio during soda-AQ pulping of sisal fibers, indicating the preferential removal of S-lignin units during cooking.

In the case of flax MWL, the HSQC spectrum (Figure 2a) indicated that it is extremely enriched in G-lignin units ( $\mathrm{S} / \mathrm{G}$ ratio 0.1), in agreement with Py-GC/MS data. In addition, the main types of linkages present in this lignin were $\beta-O-4^{\prime}$ alkyl-aryl ethers (52 substructures per 100 aromatic units), followed by phenylcoumarans (20 substructures per 100 aromatic units) and lower amounts of resinols (5 substructures per 100 aromatic units) and spirodienones (1 substructure per 100 aromatic units). Comparison with the HSQC spectrum of the residual lignin from unbleached soda-AQ flax pulp (Figure $2 b$ ) indicated a moderate decrease of $\beta-O-4^{\prime}$ alkyl-aryl ethers during soda-AQ pulping (45 substructures per 100 aromatic units), while the abundance of phenylcoumaran and resinol substructures remained largely unchanged. This fact indicates again the preferential removal of $\beta-O-4^{\prime}$ alkyl-aryl ethers during soda-AQ pulping. As occurs with the residual lignin from unbleached sisal pulp, no oxidized lignin moieties were observed in the HSQC spectrum of the residual lignin from unbleached flax pulp, indicating that depolymerization, instead of oxidation reactions, predominate during pulping. In addition, no signals from other condensed structures (i.e., stilbenes) and presumably formed during the soda-AQ process could be detected in the NMR.

The comparison of the molecular weights of the residual lignins isolated from the unbleached pulps with those of the isolated MWL (Table 3) revealed additional features regarding the structural changes in the lignin polymer during soda-AQ pulping. The residual lignin isolated from sisal unbleached pulp showed two peaks in the GPC curves, with $M_{\mathrm{w}}$ of 1350 and $4050 \mathrm{~g} \mathrm{~mol}^{-1}$ that were lower than that of the respective sisal $\operatorname{MWL}\left(M_{\mathrm{w}}\right.$ of $\left.4700 \mathrm{~g} \mathrm{~mol}^{-1}\right)$. Likewise, the residual lignin isolated from unbleached flax pulp showed two peaks in the GPC curves with $M_{\mathrm{w}}$ of 1380 and $3880 \mathrm{~g} \mathrm{~mol}^{-1}$ that were also lower than that of the respective flax MWL $\left(M_{\mathrm{w}}\right.$ of $7620 \mathrm{~g}$ $\left.\mathrm{mol}^{-1}\right)$. The strong decrease observed in the molecular weights of the isolated residual lignins, compared to their MWL, clearly indicates the degradation and depolymerization of the lignin macromolecule during pulping, while no condensation reactions seem to have taken place.

It is possible to conclude that the residual lignins from the unbleached sisal and flax soda-AQ pulps have been partially degraded and depolymerized during soda-AQ pulping, although they still present a structure quite similar to that of their native lignins in their respective raw materials, still with high abundances of $\beta-O-4^{\prime}$ alkyl-aryl ether linkages. The presence of $\beta-O-4^{\prime}$ linkages in unbleached residual pulps has also been observed in kraft pulps. ${ }^{4,5}$ Residual lignins in soda-AQ pulps seem therefore to reflect native lignin moieties entrapped into the cellulosic network thus partially avoiding their attack by chemical reagents, as also observed in residual lignins from eucalypt kraft pulps. ${ }^{9,12}$ This indicates that the most heavily modified lignin during cooking is released and incorporates into the black liquors, whereas the residual lignin in pulp remains less severely altered. For this reason, the residual lignins in the unbleached sisal and flax soda-AQ pulps are very different from each other, with the unbleached sisal pulp still being enriched in S-lignin, and the unbleached flax pulp being highly enriched in G-lignin and with important amounts of $\mathrm{H}$-lignin. This significant difference in their composition will strongly affect the behavior and fate of the residual lignins during subsequent bleaching.

3.2. Effect of the TCF and ECF Bleaching on the Lignin Structure. Interestingly, the pyrogram of the residual lignin from TCF-bleached sisal pulp was rather similar to that of the unbleached sisal pulp (Figure S1), with a predominance of Sunits (H:G:S of 2:28:70; Table 1) and a high $S / G$ ratio (2.5). No major oxidative alterations were observed in the pyrogram. Moreover, the HSQC spectrum of the residual lignin from TCF-bleached sisal pulp was also similar to that of the unbleached pulp, with the presence of important amounts of $\beta-O-4^{\prime}$ alkyl-aryl ethers (Figure 1, Table 2). The comparison of the molecular weight of the residual lignin isolated from the TCF-bleached pulp with that of the unbleached sisal pulp (Table 3) revealed additional features regarding the structural changes in the lignin polymer during TCF bleaching. The molecular weight of this residual lignin also showed two peaks in the GPC, with $M_{\mathrm{w}}$ of 1030 and $3500 \mathrm{~g} \mathrm{~mol}^{-1}$ that were only slightly lower than those observed in the unbleached sisal pulp $\left(M_{\mathrm{w}}\right.$ of 1350 and $\left.4050 \mathrm{~g} \mathrm{~mol}^{-1}\right)$. These data indicate that TCF bleaching did not affect to a great extent the lignin structure of the residual lignin. Hydrogen peroxide is thought to react mainly with the carbonyl structures present in lignin; therefore, its action on residual lignin may not be very significant since small amounts of such species are present. ${ }^{1,10}$

In contrast, the Py-GC/MS and 2D-NMR analysis of the supposedly "residual lignin material" isolated from ECFbleached sisal pulp indicated the total absence of lignin markers in this sample, which reveals that lignin has been completely removed from sisal pulp during ECF bleaching. This "residual lignin material" was probably mostly constituted by salts and small carbohydrate fragments. Probably, the high amounts of Slignin units and $\beta-O-4^{\prime}$ alkyl-aryl ether linkages in the residual lignin of the unbleached sisal pulp have made this lignin highly susceptible to degradation and removal by chlorine dioxide. The overall efficiency of chlorine dioxide is due to the combined effects of both chlorination and oxidation, especially at higher charges of chlorine dioxide. The concerted action of these two pathways on lignin results in an extremely effective combination of reactions.

In the case of flax pulps, the pyrogram of the residual lignin isolated from the TCF-bleached pulp was also similar to that of the unbleached pulp (Figure S2), with a predominance of Glignin compounds. Moreover, the Py-GC/MS and HSQC data indicated the lack of any major structural oxidation of the lignin moiety during TCF bleaching. In addition, the NMR data indicated that the TCF bleaching barely affects the structure of the residual lignin, and the main structural characteristics are maintained. The molecular weight of the residual lignin isolated from TCF-bleached flax pulp (two peaks in the GPC curve with $M_{\mathrm{w}}$ of 1390 and $3890 \mathrm{~g} \mathrm{~mol}^{-1}$ ) was also similar to that of the unbleached flax pulp $\left(M_{\mathrm{w}}\right.$ of 1390 and $\left.3890 \mathrm{~g} \mathrm{~mol}^{-1}\right)$. This fact indicates once again that TCF bleaching does not have a strong effect on the lignin composition and structure, as already observed in sisal pulp.

On the contrary, ECF bleaching strongly modified the structure of the lignin and the pyrogram of the residual lignin 
isolated from the ECF bleached flax pulp was completely different from that of the unbleached flax pulp and even from that of TCF-bleached flax pulp (Figure S2). In spite of the low lignin content in this pulp (kappa number 1), some residual lignin could still be isolated and analyzed. The pyrogram of this residual lignin showed the release of lignin markers and indicated that the lignin has suffered strong structural modifications, with the complete removal of S-lignin moieties and a strong increase in the relative abundances of $\mathrm{H}$-units ( $\mathrm{H}: \mathrm{G}: \mathrm{S}$ being 38:62:0; Table 1). It has been reported that the enrichment of H-type aromatic products produced during pulping and bleaching was not only from lignin but also from other pulp components, such as polysaccharides. ${ }^{37}$ In that paper, the authors analyzed the residual lignin in pulps "in situ" by Py-GC/MS, without prior lignin isolation, and concluded that part of the "H-units" observed in the pyrogram arise from aromatic structures formed from polysaccharides during pulping. In our work, however, we analyzed isolated residual lignins (not "in situ" in the pulps, as in previous work), and, therefore, the potential interference from polysaccharide-related moieties is highly minimized here. Furthermore, those carbohydrate-derived H-type aromatic structures would show completely different signals in the 2D-NMR spectra than the distinctive signals for lignin-derived $\mathrm{H}$-units. Also, if these $\mathrm{H}$ type units arise from polysaccharide-derived material, they should have also appeared and been concentrated in the case of sisal pulps, which is not the case. Therefore, it is obvious that the H-units observed in flax residual lignins are from authentic $\mathrm{H}$-lignin moieties and not from polysaccharide-derived material. On the other hand, an important increase of the relative abundances of oxidized lignin markers (i.e., guaiacylacetone, propiovanillone) was observed in the pyrogram, indicating that oxidative alteration of the lignin moiety also took place during ECF bleaching. The HSQC spectrum confirmed the enrichment of H-lignin and the entire removal of S-lignin units after ECF bleaching. However, and surprisingly, the HSQC spectrum clearly indicated that some amounts of the $\beta-O-4^{\prime}$ alkyl-aryl ether linkages (35 substructures per 100 aromatic units) still remained in the residual lignin from ECF-bleached flax pulp (Table 2). Most probably, the enrichment in G- and $\mathrm{H}$-lignin during soda-AQ pulping has made this lignin highly intractable and recalcitrant to chemical degradation. Interestingly, the molecular weight of this residual lignin (two peaks in the GPC curve with $M_{\mathrm{w}}$ of 1650 and $5300 \mathrm{~g} \mathrm{~mol}^{-1}$ ) is higher than that of the respective lignin from unbleached flax pulp $\left(M_{\mathrm{w}}\right.$ of 1390 and $3890 \mathrm{~g} \mathrm{~mol}^{-1}$ ), which indicates that some condensation reactions may have been taken place during ECF bleaching.

\section{CONCLUSIONS}

Soda-AQ pulping produced a preferential removal of S-lignin units and $\beta-O-4^{\prime}$ linkages. Despite this, residual lignins were rather similar to native lignin. TCF bleaching hardly affected the lignin structure, and important amounts of $\beta-O-4^{\prime}$ linkages still occurred in the TCF-bleached pulps. However, ECF bleaching caused strong modifications in the lignin structure, with the complete absence of lignin markers in the ECF-bleached sisal pulp. By contrast, residual lignin could be isolated from the ECF-bleached flax pulp, with a predominance of G- and $\mathrm{H}$-lignin units. Interestingly, $\beta-O-4^{\prime}$ linkages could still be observed indicating the high recalcitrance of flax lignin.

\section{ASSOCIATED CONTENT}

\section{S Supporting Information}

The Py-GC/MS chromatograms of the MWL from sisal fibers and the residual lignins isolated from unbleached soda-AQ TCF-bleached, and ECF-bleached sisal pulps are shown in Figure S1. The Py-GC/MS chromatograms of the MWL from flax fibers and the residual lignins isolated from unbleached soda-AQ, TCF-bleached, and ECF-bleached flax pulps are shown in Figure S2. The composition and relative molar abundances of the compounds released after Py-GC/MS of the residual lignins isolated from sisal and flax pulps and their respective MWLs are listed in Table S1. The assignments of ${ }^{13} \mathrm{C}-{ }^{1} \mathrm{H}$ correlation signals in the $2 \mathrm{D}-\mathrm{NMR}$ spectra of the isolated residual lignins are listed in Table S2. This material is available free of charge via the Internet at http://pubs.acs.org.

\section{AUTHOR INFORMATION}

\section{Corresponding Author}

*Phone: +34 954624711. Fax: +34 954624002. E-mail: delrio@ irnase.csic.es.

\section{Notes}

The authors declare no competing financial interest.

\section{ACKNOWLEDGMENTS}

We thank Gerardo Artal (CELESA, Spain) for providing the pulp samples and Xueyu Du (KTH, Stockholm, Sweden) for kindly performing GPC analyses. This study has been funded by the Spanish project AGL2011-25379, the CSIC project 201040E075, and the EU-project LIGNODECO (KBBE244362). J.R. thanks the CSIC for a JAE-DOC contract from the program "Junta para la Ampliación de Estudios" cofinanced by Fondo Social Europeo (FSE).

\section{REFERENCES}

(1) Gierer, J. The chemistry of delignification. A general concept. Holzforschung 1982, 36, 43-51.

(2) Gierer, J. Chemistry of delignification. I. General concept and reactions during pulping. Wood Sci. Technol. 1985, 19, 289-312.

(3) Froass, P. M.; Ragauskas, A. J.; Jiang, J.-E. Chemical structure of residual lignin from kraft pulp. J. Wood Chem. Technol. 1996, 16, 347365 .

(4) Froass, P. M.; Ragauskas, A. J.; Jiang, J.-E. Nuclear magnetic resonance studies. 4. Analysis of residual lignin after kraft pulping. Ind. Eng. Chem. Res. 1998, 37, 3388-3394.

(5) Gellerstedt, G.; Lindfors, E. L.; Lapierre, C.; Monties, B. Structural changes in lignin during kraft cooking. Part 2. Characterization by acidolysis. Sven. Papperstidn. 1984, 87, 61-67.

(6) Gellerstedt, G.; Pranda, J.; Lindfors, E. L. Structural and molecular properties of residual birch kraft lignins. J. Wood Chem. Technol. 1994, 14, 467-482.

(7) Gellerstedt, G.; Majtnerova, A.; Zhang, L. Towards a new concept of lignin condensation in kraft pulping. Initial results. C. $R$ Biol. 2004, 327, 817-826.

(8) Gellerstedt, G.; Lindfords, E. L. Structural changes in lignin during kraft pulping. Holzforschung 1984, 38, 151-158.

(9) Ibarra, D.; Chavez, M. I.; Rencoret, J.; del Río, J. C.; Gutierrez, A.; Romero, J.; Camarero, S.; Martinez, M. J.; Jimenez-Barbero, J.; Martinez, A. T.. Lignin modification during Eucalyptus globulus kraft pulping followed by totally chlorine-free bleaching: A two-dimensional nuclear magnetic resonance, Fourier transform infrared, and pyrolysisgas chromatography/mass spectrometry study. J. Agric. Food Chem. 2007, 55, 3477-3490.

(10) Shing, A. Delignification mechanisms using oxygen and hydrogen peroxide. TAPPI Symposium on Oxygen Delignification; Tappi Press: Atlanta, 1990; pp 53-59. 
(11) del Río, J. C.; Gutiérrez, A.; Romero, J.; Martínez, M. J.; Martínez, A. T. Identification of residual lignin markers in eucalypt kraft pulp by Py-GC-MS. J. Anal. Appl. Pyrol. 2001, 58/59, 425-439.

(12) Ibarra, D.; del Río, J. C.; Gutiérrez, A.; Rodríguez, I. M.; Romero, J.; Martínez, M. J.; Martínez, A. T. Chemical characterization of residual lignins from eucalypt paper pulps. J. Anal. Appl. Pyrol. 2005, $74,116-122$.

(13) Gellerstedt, G.; Heuts, L. Changes in the lignin structure during a totally chlorine free bleaching sequence. J. Pulp Paper Sci. 1997, 23, 335-340.

(14) Gellerstedt, G.; Zhang, L. Chemistry of TCF bleaching with oxygen and hydrogen peroxide. In Oxidative Delignification Chemistry - Fundamentals and Catalysis; Argyropoulos, D. S., Ed.; ACS Symposium Series 785, 2001; pp 61-72.

(15) Gellerstedt, G.; Lindfords, E. L.; Petterson, M.; Robert, D. Reactions of lignin in chlorine dioxide bleaching of kraft pulps. Res. Chem. Intermed. 1995, 21, 441-456.

(16) Bose, S. K.; Omori, S.; Kanungo, D.; Francis, R. D.; Shin, N.-H. Mechanistic differences between kraft and soda/AQ pulping. Part 1: Results from wood chips and pulps. J. Wood Chem. Technol. 2009, 29, 214-226.

(17) Kanungo, D.; Francis, R. C.; Shin, N.-H. Mechanistic differences between kraft and soda/AQ pulping. Part 2: Results from lignin model compounds. J. Wood Chem. Technol. 2009, 29, 227-240.

(18) del Río, J. C.; Gutierrez, A.; Martinez, A. T. Identifying acetylated lignin units in non-wood fibers using pyrolysis-gas chromatography/mass spectrometry. Rapid Commun. Mass Spectrom. 2004, 18, 1181-1185.

(19) del Río, J. C.; Marques, G.; Rencoret, J.; Martinez, A. T.; Gutierrez, A. Occurrence of naturally acetylated lignin units. J. Agric. Food Chem. 2007, 55, 5461-5468.

(20) del Río, J. C.; Rencoret, J.; Marques, G.; Gutierrez, A.; Ibarra, D.; Santos, J. I.; Jimenez-Barbero, J.; Zhang, L. M.; Martinez, A. T. Highly acylated (acetylated and/or $p$-coumaroylated) native lignins from diverse herbaceous plants. J. Agric. Food Chem. 2008, 56, 95259534.

(21) del Río, J. C.; Rencoret, J.; Gutiérrez, A.; Nieto, L.; JiménezBarbero, J.; Martínez, A. T. Structural characterization of guaiacyl-rich lignins in flax (Linum usitatissimum) fibers and shives. J. Agric. Food Chem. 2011, 59, 11088-11099.

(22) del Río, J. C.; Gutiérrez, A.; Rodríguez, I. M.; Ibarra, D.; Martínez, A. T. Composition of non-woody plant lignins and cinnamic acids by Py-GC/MS, Py/TMAH and FT-IR. J. Anal. Appl. Pyrolysis 2007, 79, 39-46.

(23) Faix, O.; Meier, D.; Fortmann, I. Thermal degradation products of wood. Holz Roh-Werstoff 1990, 48, 351-354.

(24) Ralph, J.; Hatfield, R. D. Pyrolysis-GC-MS characterization of forage materials. J. Agric. Food Chem. 1991, 39, 1426-1437.

(25) Capanema, E. A.; Balakshin, M. Y.; Chen, C. L.; Gratzl, J. S.; Gracz, H.. Structural analysis of residual and technical lignins by H-1C-13 correlation 2D NMR-spectroscopy. Holzforschung 2001, 55, 302-308.

(26) del Río, J. C.; Rencoret, J.; Marques, G.; Li, J. B.; Gellerstedt, G.; Jimenez-Barbero, J.; Martinez, A. T.; Gutierrez, A. Structural characterization of the lignin from jute (Corchorus capsularis) fibers. J. Agric. Food Chem. 2009, 57, 10271-10281.

(27) Liitia, T. M.; Maunu, S. L.; Hortling, B.; Toikka, M.; Kilpeläinen, I. Analysis of technical lignins by two- and three-dimensional NMR spectroscopy. J. Agric. Food Chem. 2003, 51, 2136-2143.

(28) Martinez, A. T.; Rencoret, J.; Marques, G.; Gutierrez, A.; Ibarra, D.; Jimenez-Barbero, J.; del Río, J. C. Monolignol acylation and lignin structure in some nonwoody plants: A 2D NMR study. Phytochemistry 2008, 69, 2831-2843.

(29) Ralph, S. A.; Ralph, J.; Landucci, L. NMR database of lignin and cell wall model compounds; US Forest Prod. Lab., One Gifford Pinchot Dr., Madison, WI 53705, 2004. http://ars.usda.gov/Services/ docs.htm?docid=10491 (accessed January 2009).

(30) Ralph, J.; Landucci, L. L. NMR of Lignins. In Lignin and Lignans; Advances in Chemistry; Heitner, C., Dimmel, D. R., Schmidt, J.
A., Eds.; CRC Press (Taylor \& Francis Group): Boca Raton, FL, 2010; pp 137-234.

(31) Ralph, J.; Marita, J. M.; Ralph, S. A.; Hatfield, R. D.; Lu, F.; Ede, R. M.; Peng, J.; Quideau, S.; Helm, R. F.; Grabber, J. H.; Kim, H.; Jimenez-Monteon, G.; Zhang, Y.; Jung, H.-J. G.; Landucci, L. L.; MacKay, J. J.; Sederoff, R. R.; Chapple, C.; Boudet, A. M. Solutionstate NMR of lignins. In Advances in Lignocellulosics Characterization; Argyropoulos, D. S., Ed.; TAPPI Press: Atlanta, GA, 1999; pp 55-108.

(32) Rencoret, J.; Marques, G.; Gutierrez, A.; Ibarra, D.; Li, J.; Gellerstedt, G.; Santos, J. I.; Jimenez-Barbero, J.; Martinez, A. T.; del Río, J. C. Structural characterization of milled wood lignins from different eucalypt species. Holzforschung 2008, 62, 514-526.

(33) Rencoret, J.; Marques, G.; Gutierrez, A.; Nieto, L.; JimenezBarbero, J.; Martinez, A. T.; del Río, J. C. Isolation and structural characterization of the milled-wood lignin from Paulownia fortunei wood. Ind. Crops Prod. 2009, 30, 137-143.

(34) Rencoret, J.; Gutiérrez, A.; Nieto, L.; Jiménez-Barbero, J.; Faulds, C. B.; Kim, H.; Ralph, J.; Martínez, A. T.; del Río, J. C. Lignin composition and structure in young versus adult Eucalyptus globulus plants. Plant Physiol. 2011, 155, 667-682.

(35) Björkman, A. Studies on finely divided wood. Part I. Extraction of lignin with neutral solvents. Sven. Papperstidn. 1956, 59, 477-485.

(36) Bocchini, P.; Galletti, G. C.; Camarero, S.; Martínez, A. T. Absolute quantitation of lignin pyrolysis products using an internal standard. J. Chromatogr., A 1997, 773, 227-232.

(37) Ohra-aho, T. L; Tenkanen, M.; Tamminen, T. Direct analysis of lignin and lignin-like components from softwood kraft pulp by PyGC/MS techniques. J. Anal. Appl. Pyrolysis 2005, 74, 123-128. 


\section{Structural modifications of residual lignins}

\section{from sisal and flax pulps during soda-AQ}

\section{pulping and TCF/ECF bleaching}

Jorge Rencoret $^{1}$, Gisela Marques ${ }^{1}$, Ana Gutiérrez ${ }^{1}$, Jesús Jiménez-Barbero ${ }^{2}$, Ángel T. Martínez ${ }^{2}$ and José C. del Río ${ }^{1 *}$

${ }^{1}$ Instituto de Recursos Naturales y Agrobiología de Sevilla, CSIC, P.O. Box 1052, E-41080-

Seville, Spain

${ }^{2}$ Centro de Investigaciones Biológicas, CSIC, Ramiro de Maeztu 9, E-28040 Madrid, Spain

*Corresponding author: Tel:+34954624711; Fax: +34 954624002; E-mail: delrio@irnase.csic.es 
Table S1. Composition and Relative Molar Abundances of the Compounds Released after PyGC/MS of the Residual Lignins Isolated from Sisal and Flax pulps, and Their Respective MWLs

\begin{tabular}{|c|c|c|c|c|c|c|c|c|c|}
\hline \multirow[b]{2}{*}{ Label } & \multirow[b]{2}{*}{ Compound } & \multirow[b]{2}{*}{ MWL } & \multicolumn{3}{|c|}{ sisal pulps } & \multirow[b]{2}{*}{ MWL } & \multicolumn{3}{|c|}{ flax pulps } \\
\hline & & & $\overline{\text { Unbleached }}$ & TCF & $\overline{\mathrm{ECF}}$ & & Unbleached & TCF & ECF \\
\hline 1 & phenol & 0.4 & 0.7 & 0.3 & - & 2.2 & 2.6 & 2.2 & 8.4 \\
\hline 2 & hydroxybenzaldehyde & 0.0 & 0.3 & 0.2 & - & 0.0 & 0.4 & 0.6 & 4.5 \\
\hline 3 & 2-methylphenol & 0.2 & 0.4 & 0.4 & - & 1.6 & 2.1 & 1.3 & 4.1 \\
\hline 4 & 4-methylphenol & 0.2 & 1.2 & 0.8 & - & 5.1 & 2.9 & 3.2 & 13.6 \\
\hline 5 & guaiacol & 3.7 & 5.4 & 4.5 & - & 13.0 & 14.8 & 16.5 & 19.1 \\
\hline 6 & C2-phenol & 0.2 & 0.6 & 0.4 & - & 1.9 & 1.8 & 2.4 & 1.3 \\
\hline 7 & methoxybenzaldehyde & 0.0 & 0.4 & 0.3 & - & 0.0 & 1.0 & 0.6 & 6.1 \\
\hline 8 & methylguaiacol isomer & 0.3 & 0.9 & 0.7 & - & 0.0 & 1.3 & 0.5 & 0.0 \\
\hline 9 & 4-methylguaiacol & 3.6 & 7.2 & 7.0 & - & 21.2 & 20.7 & 18.2 & 9.3 \\
\hline 10 & 4-ethylguaiacol & 1.6 & 3.6 & 3.9 & - & 5.4 & 6.7 & 7.0 & 3.2 \\
\hline 11 & methoxycatechol & 0.0 & 1.5 & 2.9 & - & 0.0 & 0.0 & 0.0 & 0.0 \\
\hline 12 & 4-vinylguaiacol & 4.2 & 6.3 & 4.8 & - & 14.7 & 15.4 & 15.2 & 4.5 \\
\hline 13 & syringol & 15.1 & 13.8 & 11.9 & - & 3.4 & 2.4 & 3.1 & 0.0 \\
\hline 14 & eugenol & 1.0 & 0.8 & 0.9 & - & 1.9 & 1.9 & 1.7 & 2.3 \\
\hline 15 & 4-propylguaiacol & 0.1 & 0.0 & 0.0 & - & 0.0 & 0.8 & 0.7 & 0.9 \\
\hline 16 & syringol-isomer & 0.0 & 1.1 & 1.9 & - & 0.0 & 0.0 & 0.0 & 0.0 \\
\hline 17 & cis-isoeugenol & 1.1 & 0.8 & 0.9 & - & 1.4 & 1.9 & 1.5 & 1.1 \\
\hline 18 & vanillin & 1.5 & 1.5 & 1.3 & - & 3.1 & 4.2 & 4.6 & 4.4 \\
\hline 19 & 4-methylsyringol & 14.2 & 16.0 & 17.1 & - & 3.3 & 2.3 & 1.5 & 0.0 \\
\hline 20 & trans-isoeugenol & 4.4 & 2.5 & 2.3 & - & 8.7 & 7.0 & 8.1 & 3.1 \\
\hline 21 & acetoguaiacone & 0.5 & 1.1 & 0.5 & - & 1.6 & 1.4 & 1.4 & 1.8 \\
\hline 22 & vanillic acid methyl ester & 0.0 & 0.0 & 0.0 & - & 0.3 & 0.4 & 0.5 & 0.5 \\
\hline 23 & 4-ethylsyringol & 1.6 & 3.6 & 2.9 & - & 0.6 & 0.6 & 0.3 & 0.0 \\
\hline 24 & guaiacylacetone & 0.4 & 1.3 & 0.3 & - & 1.9 & 2.4 & 4.5 & 8.7 \\
\hline 25 & 4-vinylsyringol & 11.0 & 7.4 & 6.9 & - & 1.8 & 1.9 & 1.3 & 0.0 \\
\hline 26 & 4-allylsyringol & 4.5 & 2.6 & 3.1 & - & 0.6 & 0.3 & 0.3 & 0.0 \\
\hline 27 & propiovanillone & 0.0 & 0.0 & 0.0 & - & 0.9 & 0.7 & 1.2 & 3.2 \\
\hline 28 & 4-propylsyringol & 0.2 & 0.5 & 0.4 & - & 0.1 & 0.0 & 0.0 & 0.0 \\
\hline 29 & cis-4-propenylsyringol & 3.9 & 2.0 & 2.8 & - & 0.6 & 0.3 & 0.3 & 0.0 \\
\hline 30 & syringaldehyde & 6.1 & 3.2 & 4.7 & - & 0.9 & 0.2 & 0.3 & 0.0 \\
\hline 31 & trans-4-propenylsyringol & 12.4 & 6.6 & 9.1 & - & 2.6 & 0.9 & 0.7 & 0.0 \\
\hline 32 & acetosyringone & 1.6 & 2.1 & 2.0 & - & 0.6 & 0.3 & 0.1 & 0.0 \\
\hline 33 & syringylacetone & 1.4 & 2.9 & 1.9 & - & 0.5 & 0.2 & 0.1 & 0.0 \\
\hline 34 & propiosyringone & 0.7 & 1.1 & 1.0 & - & 0.2 & 0.1 & 0.1 & 0.0 \\
\hline 35 & trans-sinapaldehyde & 4.0 & 0.7 & 2.2 & - & 0.0 & 0.0 & 0.0 & 0.0 \\
\hline
\end{tabular}


Table S2. Assignments of ${ }^{13} \mathrm{C}-{ }^{1} \mathrm{H}$ Correlation Signals in the 2D-NMR Spectra of the Residual Lignins Isolated from the Different Pulps and their MWLs.

\begin{tabular}{|c|c|c|}
\hline $\begin{array}{l}\text { Label } \\
\end{array}$ & $\delta_{\mathrm{C}} / \delta_{\mathrm{H}}(\mathrm{ppm})$ & Assignment \\
\hline$\overline{\mathrm{B}_{\beta}}$ & $53.5 / 3.46$ & $\mathrm{C}_{\beta}-\mathrm{H}_{\beta}$ in phenylcoumaran substructures (B) \\
\hline $\mathrm{C}_{\beta}$ & $53.5 / 3.06$ & $\mathrm{C}_{\beta}-\mathrm{H}_{\beta}$ in resinol substructures $(\mathbf{C})$ \\
\hline -OMe & $55.6 / 3.73$ & $\mathrm{C}-\mathrm{H}$ in methoxyls \\
\hline $\mathrm{A}_{\gamma}$ & $59.4 / 3.40$ and 3.72 & $\mathrm{C}_{\gamma}-\mathrm{H}_{\gamma}$ in $\beta-O-4^{\prime}$ substructures (A) \\
\hline $\mathrm{D}_{\beta}$ & $59.6 / 2.75$ & $\mathrm{C}_{\beta}-\mathrm{H}_{\beta}$ in spirodienone substructures (D) \\
\hline $\mathrm{A}_{\gamma}^{\prime}$ & $62.7 / 3.83-4.30$ & $\mathrm{C}_{\gamma}-\mathrm{H}_{\gamma}$ in $\gamma$-acylated $\beta-O-4^{\prime}$ substructures (A') \\
\hline $\mathrm{C}_{\gamma}$ & 71.0/3.83 and 4.19 & $\mathrm{C}_{\gamma}-\mathrm{H}_{\gamma}$ in resinol substructures $(\mathbf{C})$ \\
\hline $\mathrm{A}_{\alpha} / \mathrm{A}_{\alpha}^{\prime}$ & $71.7 / 4.86$ & $\mathrm{C}_{\alpha}-\mathrm{H}_{\alpha}$ in $\beta-O-4$ ' substructures linked to a $\mathrm{S}$ unit (A. $\mathbf{A}^{\prime}$ ) \\
\hline $\mathrm{D}_{\beta^{\prime}}$ & 79.3/4.11 & $\mathrm{C}_{\beta}-\mathrm{H}_{\beta^{\prime}}$ in spirodienone substructures (D) \\
\hline $\mathrm{A}_{\beta(\mathrm{G})}^{\prime}$ & $80.8 / 4.58$ & $\mathrm{C}_{\beta}-\mathrm{H}_{\beta}$ in $\gamma$-acylated $\beta-O-4^{\prime}$ substructures linked to a $\mathrm{G}$ unit (A') \\
\hline $\mathrm{D}_{\alpha}$ & $81.2 / 5.09$ & $\mathrm{C}_{\alpha}-\mathrm{H}_{\alpha}$ in spirodienone substructures (D) \\
\hline $\mathrm{A}_{\beta(\mathrm{H})}$ & $82.9 / 4.48$ & $\mathrm{C}_{\beta}-\mathrm{H}_{\beta}$ in $\beta-O-4^{\prime}$ substructures linked to a $\mathrm{H}$ unit (A) \\
\hline $\mathrm{A}_{\beta(\mathrm{G})} / \mathrm{A}_{\beta(\mathrm{S})}^{\prime}$ & 83.5/4.28 and 83.0/4.32 & $\begin{array}{l}\mathrm{C}_{\beta}-\mathrm{H}_{\beta} \text { in } \beta-O-4^{\prime} \text { substructures linked to a } \mathrm{G} \text { unit }(\mathbf{A}) \text { and in } \gamma- \\
\text { acylated } \beta-O-4^{\prime} \text { substructures linked to a } \mathrm{S} \text { unit }\left(\mathbf{A}^{\prime}\right)\end{array}$ \\
\hline $\mathrm{D}_{\alpha^{\prime}}$ & $84.7 / 4.76$ & $\mathrm{C}_{\alpha}-\mathrm{H}_{\alpha^{\prime}}$ in spirodienone substructures (D) \\
\hline $\mathrm{C}_{\alpha}$ & $84.8 / 4.67$ & $\mathrm{C}_{\alpha}-\mathrm{H}_{\alpha}$ in resinol substructures $(\mathbf{C})$ \\
\hline $\mathrm{A}_{\beta(\mathrm{S})}$ & $85.8 / 4.11$ & $\mathrm{C}_{\beta}-\mathrm{H}_{\beta}$ in $\beta-O-4^{\prime}$ substructures linked to a $\mathrm{S}$ unit (A) \\
\hline $\mathrm{B}_{\alpha}$ & $86.8 / 5.46$ & $\mathrm{C}_{\alpha}-\mathrm{H}_{\alpha}$ in phenylcoumaran substructures (B) \\
\hline $\mathrm{S}_{2.6}$ & 103.8/6.69 & $\mathrm{C}_{2.6}-\mathrm{H}_{2.6}$ in etherified syringyl units (S) \\
\hline $\mathrm{G}_{2}$ & $110.9 / 6.99$ & $\mathrm{C}_{2}-\mathrm{H}_{2}$ in guaiacyl units $(\mathbf{G})$ \\
\hline $\mathrm{H}_{3.5}$ & $114.9 / 6.74$ & $\mathrm{C}_{3.5}-\mathrm{H}_{3.5}$ in $p$-hydroxyphenyl units $(\mathbf{H})$ \\
\hline $\mathrm{G}_{5}$ & 114.9/6.72 and 6.94 & $\mathrm{C}_{5}-\mathrm{H}_{5}$ in guaiacyl units $(\mathbf{G})$ \\
\hline $\mathrm{G}_{6}$ & $118.7 / 6.77$ & $\mathrm{C}_{6}-\mathrm{H}_{6}$ in guaiacyl units $(\mathbf{G})$ \\
\hline $\mathrm{H}_{2.6}$ & 128.0/7.23 & $\mathrm{C}_{2.6}-\mathrm{H}_{2.6}$ in $p$-hydroxyphenyl units $(\mathbf{H})$ \\
\hline
\end{tabular}



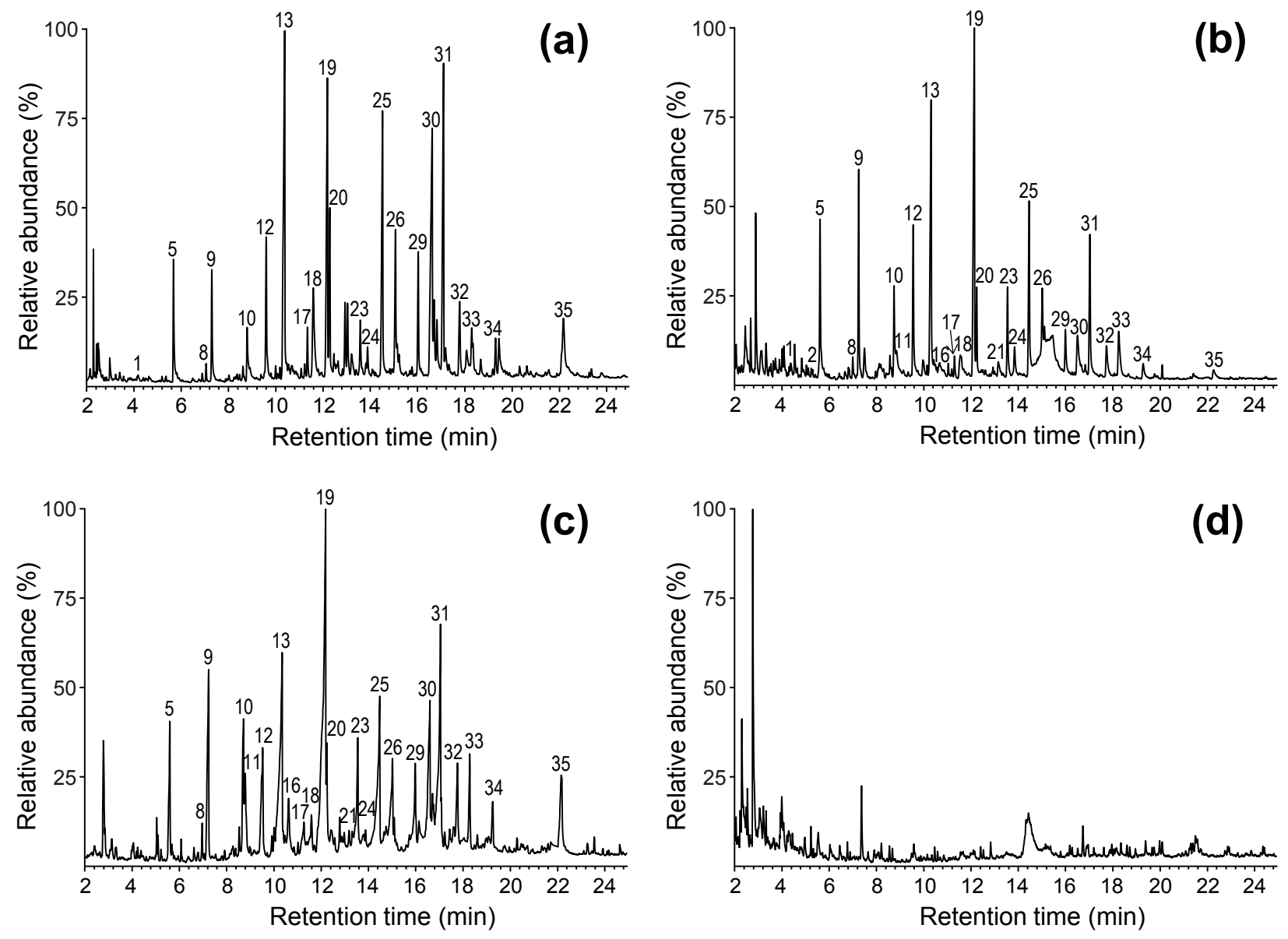

Figure S1. Py-GC/MS chromatograms of the MWL from sisal fibers (a), and the residual lignins isolated from unbleached soda-AQ sisal pulp (b), TCF-bleached sisal pulp (c), and ECFbleached sisal pulp (d). The identities and relative abundances of the released compounds are listed in Table S1. 

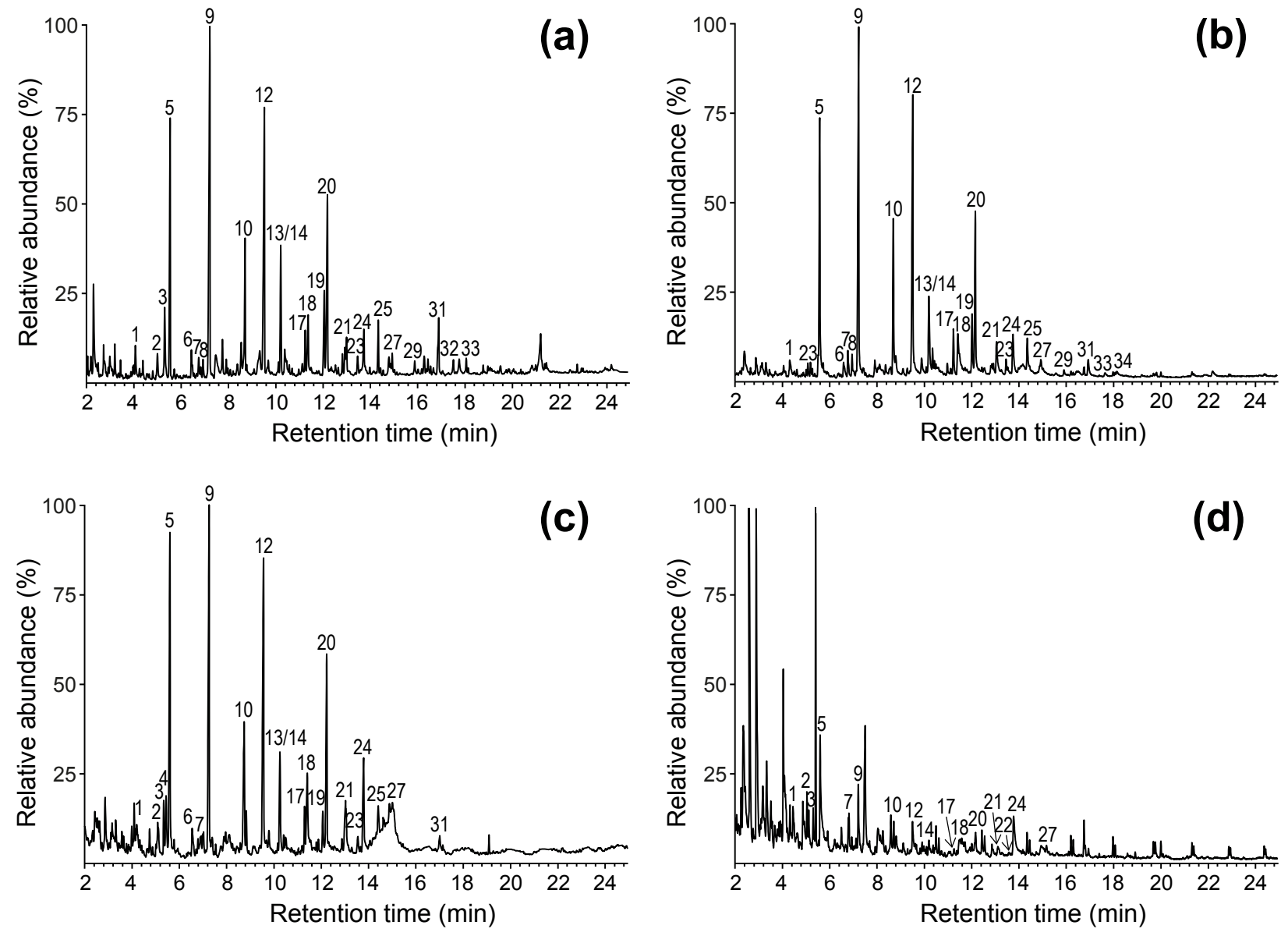

Figure S2. Py-GC/MS chromatograms of the MWL from flax fibers (a) and the residual lignins isolated from unbleached soda-AQ flax pulp (b), TCF-bleached flax pulp (c), and ECF-bleached flax pulp (d). The identities and relative abundances of the released compounds are listed in Table S1. 